\title{
Helicopter main rotor blade injury to the head with survival
}

\author{
JRP Gibbons \\ MBE, TD, FRCS, FICS, FCCP \\ Honorary Consultant to the Army in Northern Ireland \\ Surgeon
}

Royal Victoria Hospital, Belfast.

Capt L Orr

BSc, MB, ChB, RAMC

$\mathrm{SHO}$ in Surgery

Duke of Connaught's Unit, Musgrave Park Hospital, Belfast BFPO 801.

\section{DJ Carr}

BSc, PhD, ASMIMat

Defence Clothing and Textiles Agency, Colchester C02 7SS.

\section{CER Gibbons \\ FRCS, FRCSI \\ Registrar,}

Royal Surrey County Hospital, Guildford.

SUMMARY: A case of soldier surviving a major helicopter rotor blade injury occurring in daylight is described an the limited literature on the subject is discussed.

\section{Introduction}

Rotor blade injuries are uncommon in the Armed Forces because of continual safety training and protection in relation to the use of helicopters. Rarely, accidents do still happen as a reminder that even with acute awareness of ground movements, incidents will occur. A review of the total United States Army rotor blade accidents between 1972 and 1991 reported 24 strike injuries, 12 of which involved the main rotor. Eleven died, the majority from a crushed skull or decapitation. It is of interest that 22 of these injuries occurred during daylight hours with no accidents occurring at night.

We report a head injury in a soldier who survived following a major main rotor blade injury occurring in daylight. The helmet gave very good protection and technical information is given in this paper. The major clinical problem remaining is a profound 8th nerve deafness, but he made an otherwise full recovery.

\section{Case Report}

A 26 year old soldier was on operational duty with a platoon in South Armagh. The Puma helicopter in which he was travelling was hovering on the side of a hill. After deplaning he was struck on the left side of the helmet by the main rotor blade and was rendered immediately unconscious. He was taken to the nearest hospital which was at Newry. On examination he had a Glasgow Coma Scale (GCS) of $12 / 15$. There was a $2 \mathrm{~cm}$ stellate laceration of his left parietal region but no other sign of external injury. The cervical region was kept stabilised and he was transferred for neurological assessment to the Royal Victoria Hospital (RVH) in Belfast.

At the RVH a full neurological examination and a computerised axial tomographic radiological examination (CAT scan) was done. At this time his GCS had improved and there was no gross neurological deficit. There was no evidence of a marked subdural haemorrhage, skull fracture or fracture/dislocation of the cervical and upper thoracic spine. The laceration was cleaned and sutured and he was transferred to the Duke of Connaught's Unit in Belfast, the military hospital for Northern Ireland.

\section{Clinical Examination}

On admission to the Duke of Connaught's Unit he was conscious but drowsy. Examination revealed a sutured $\widetilde{ }$ laceration to the left parietal region. A left periorbital haemorrhage was present, but examination of the eyes? and fundi was normal. There was complete deafness inco 
the left ear and a blood clot was visible in the left anditory meatus. Examination of the cardiovascular and respiratory systems was unremarkable.

Further examination by an ENT consultant confirmed a hearing loss on the left side and a perforated left tympanic membrane. There was also thought to be a fracture through the left cochlea.

He progressed well with no further neurological symptoms apart from mild intermittent headache. He was discharged from hospital after 10 days and has since returned to his unit remaining under the care of the ENT Surgeons.

\section{Discussion}

Helicopter main rotor blade injuries are uncommon in both civilian and military operations (1). Apart from four reports analysing helicopter accidents, little detailed information has been published. Kiel reviewed rotor blade injuries between 1948 and 1964 from data produced by the United States Army Board for Aviation Accident Research and the Civil Aeronautics Board (2). Seventeen fatal accidents were reported, almost evenly divided between military and civilian helicopters. In Kiel's series the main rotor was involved in 5 of the 17 cases, 3 of the fatalities being ground crew with one passenger and one bystander being fatally injured. Some of these injuries occurred when operating a Bell H13 helicopter, which with a main rotor idling at 250 revolutions per minute produces a speed of 312 miles per hour at the tip of the rotating main blade.

In 1982 Collins analysed 319 propeller accidents occurring in the USA during the period 1965 to 1979 (3). Of these 319 injuries, helicopters were involved in 46 incidents, of which $50 \%$ were fatal. No analysis is made of injuries occurring as a strike from main or tail rotor blades, but he did observe that many accidents occurred at dusk or in darkness.

It was also suggested that blades should be painted, possibly with alternate black and white stripes to provide a more conspicuous revolving blade. For tactical reasons this is unlikely to be put into effect in military helicopters. A review of British Army Air Corps helicopter accidents occurring between 1971 and 1982 was published in 1984. This involved all types of accidents including those occurring in the Falklands War. Only three tail rotor accidents were reported, all in Scout helicopters. The casualties were passengers, two of whom suffered fatal injuries. The specific details of injury are not recorded.

Crowley and Geyer produced a full review of all US Army helicopter rotor blade injury between 1972 and 1991 (4). In this twenty year review twenty four blade injuries were analysed, of which twelve involved the main rotor blades. In this number there were twenty head injuries, of which nine involved the tail rotor and one person was struck by both. Ten out of eleven fatalities were head injuries which were due to crushed skulls, decapitation or avulsion of brain. Some $63 \%$ of casualties

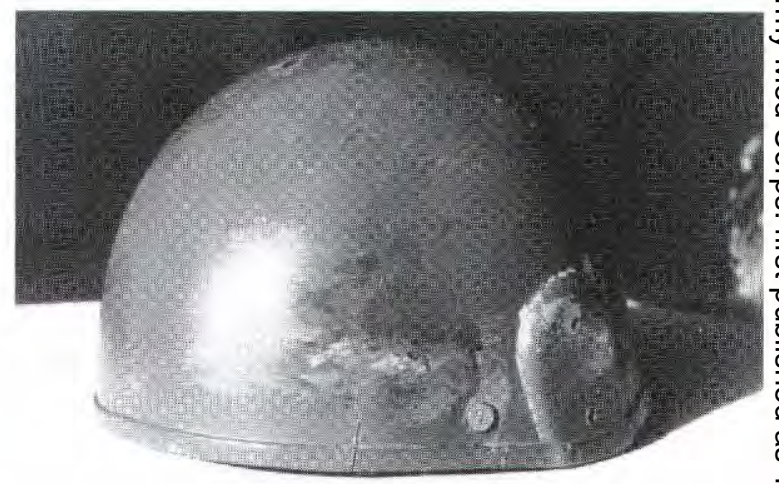

Fig 1. Helmet GS Mark 6

were flight or ground crews who should be well aware of the drills when deplaning or enplaning a helicopter. It is also significant that twenty two out of twenty four incidents occurred during daylight hours.

Air crew and ground staff are trained in helicopter $\overbrace{N}$ drills, yet in spite of this, two fatalities involved air crew $\frac{\dot{\omega}}{\omega}$ walking up a slope away from the aircraft and thus were elevating their heads into the main rotor blades pathway

In our reported case, the soldier was a tall man wh was struck when walking away from the aircraft, up a व⿱⺈ incline. The GS6 helmet (Fig. 1) although split by the rotary blades, was protective and saved him from a fat $\vec{\theta}$ injury. Crowley and Geyser also quote three cases i8. which helmets provided protection and in which on relatively mild injury occurred (4).

All flight crews and ground staff must be reminded of the danger of rotating blades. Helmets do offer some $\stackrel{2}{\circ}$ protection and should be worn in an operational situation. $\mathbb{Q}$ But, even one strike injury is one too many and all $\overrightarrow{\overrightarrow{0}}$ involved should always be instructed in the safety drills 3 for helicopter operations.

\section{Acknowledgements}

We thank Mrs Jayne Martin for the typing of the manuscript, Lt Col JS Crowley US Army and Dr Ann Williams for advice.

\section{REFERENCES}

1. VYRnWY-JONES P. A Review of Army Air Corps Helicopter Accidents 1971-1982. Aviat Space Environ Med 1985; 56: 403-9.

2. KIEL FW. Helicopter Rotor Blade Injuries. Aerosp Med 1965; 35: 668-70.

3. Collins We, Mastrullo ar, Taylor DK, Grape P. An Analysis of Civil Aviation Propeller to Person $N$ Accidents 1965 - 1979. Aviat Space Environ Med 1982; 53: 485-62.

4. Crowley JS, Geyer SL. Helicopter Rotor Blade Injury. A Persistent Safety Hazard in the US Army. श Aviat Space Environ Med 1993; 64: 854-8. 